\title{
9 Energy-saving innovations and economy-wide rebound effects
}

\author{
Gioele Figus, Karen Turner \\ and Antonios Katris
}

\section{Introduction}

A common characteristic of human societies is the ongoing effort to achieve the same or better outcomes with less use of natural resources. Especially during the industrial revolution, steam engines were increasingly used to provide mechanical power and to increase the productivity of labour. Engines, however, required an energy source to operate and the fuel of choice at the time was coal. Even back then, engineers were seeking to improve the efficiency by which engines were using coal with a view to reduce the resource requirements and therefore the associated costs. However, as Jevons (1865) first identified, the improvements in the energy efficiency of steam engines made the use of those engines more attractive, thereby accelerating the use of coal. This was partly due to the fact that steam engines were used in the production of iron, so efficiency improvements reduced the cost of iron, thus increasing its consumption, and indirectly the use of coal. The net result was that continuous improvements in efficiency of steam engines throughout the industrial revolution were accompanied by continuous increases in the consumption of coal - the so-called 'Jevons' paradox'.

Jevons' paradox is an extreme example of a more general phenomenon, known as the 'rebound effect'. This is an umbrella term for a variety of economic responses to improved energy efficiency, whose net result is to reduce the energy savings achieved. For example, people may take the benefits of improved insulation in the form of warmer homes rather than realising the full potential reductions in energy consumption (a direct rebound effect). Alternatively, they may spend the cost savings on other goods and services that also require energy and emissions to be produced (an indirect rebound effect). One hundred and fifty years after Jevons, the rebound effect is still closely associated with energy efficiency improvements in both production and consumption (Khazzoom, 1980). Its existence makes some commentators sceptical towards the use of energy efficiency policies as a climate change mitigation tool. ${ }^{1}$ The fact that a part of the technologically feasible energy savings is almost inevitably eroded creates the impression that energy efficiency improvements deliver less than what the allocated funds can theoretically achieve. However, this neglects the fact that reductions in energy consumption may not be the only goal. 
In 2014, the International Energy Agency (IEA) published a study detailing how energy efficiency improvements can serve a multitude of purposes including, but not limited to, climate change mitigation (IEA, 2014). ${ }^{2}$ According to IEA, energy efficiency improvements provide benefits in five main fields, namely: macroeconomic, public budget, health and wellbeing, industry and energy delivery. In each of these fields, IEA identified specific areas that could benefit from efficiency improvements, with the nature and magnitude of those benefits being closely related to how the efficiency improvements are implemented. This 'multiple benefits' approach not only emphasises the wide-ranging benefits of energy efficiency, but also crucially highlights the true source and nature of the rebound effect. The rebound effect is not an observable phenomenon that reduces the value of energy efficiency policies. Rather it is associated with the fact that improvements in energy use may generate a wide array of positive outcomes throughout the economy and society.

For example, improvements in the energy efficiency of domestic boilers will make heating cheaper and households may take advantage of this by enjoying higher levels of thermal comfort. This will increase their 'consumer surplus'3 which contributes to aggregate social welfare - as will the impacts in other fields identified by the IEA. Energy consumption will normally be reduced, but not by as much as it would have been in the absence of the increased demand for heating. Since energy consumption contributes to climate change, it imposes costs on other people both now and in the future. But these 'external costs' must be set against the multiple benefits of the efficiency improvement, including the benefits to consumers of warmer homes. Provided the latter are larger than the former, energy efficiency improvements provide net benefits to society.

In our Engineering and Physical Sciences Research Council End Use Energy Demand (EPSRC EUED) research project 'Energy saving innovations and economy-wide rebound effects', we explore the potential, economy-wide socioeconomic impacts of improved energy efficiency. In the case studies presented in this chapter we examine the impact of improved energy efficiency in households in both the UK and Scotland, as a devolved nation within the UK. Using economy-wide macroeconomic modelling we identify how a reduction in the physical energy use requirements of different household income groups impacts the UK and Scottish economies. Moreover, since energy efficiency policies could serve as a means to pursue multiple policy objectives, we explore options for funding energy efficiency programmes from the public budget and analyse the potential impact of these options.

Through these case studies we seek to present evidence that there are more important elements to energy efficiency policy than just the changes in energy use. Therefore, policy consideration needs to adopt a wider view of the impacts, rather than focusing solely on potential rebound effects. In each case, we estimate the rebound effects associated with the energy efficiency improvements. But as discussed above, these effects may be a barrier to implementing energy efficiency policies owing to the negative connotations of the 'lost' energy savings. We therefore propose an alternative metric for evaluating the 
effectiveness of energy efficiency policies in reducing energy use and/or carbon emissions. This is the Carbon (or Energy) Saving Multiplier, which indicates the total ${ }^{4}$ carbon or energy savings for each unit of carbon or energy saved by the target of the energy efficiency policy.

This chapter is structured as follows. The next section summarises the results of our analysis of the impact of household energy efficiency improvements, focusing on UK and Scottish households. The following section proposes an alternative metric to evaluate energy efficiency policies and applies this metric to an illustrative household energy efficiency improvement example. The concluding section provides remarks and reflections on potential future steps.

\section{Analyses of the economy-wide impact of improved household energy efficiency}

When considering energy efficiency policies, significant attention has been allocated to the associated rebound effect. This has driven a growing literature focused upon estimating the direct and indirect rebound effects following energy efficiency improvements by households. By combining econometric analysis and Input-Output $(\mathrm{IO})$ analytical techniques, a number of studies have estimated the effectiveness of energy efficiency policies in reducing energy use and/or carbon emissions at the economy-wide level (see for example Brännlund et al., 2007; Chitnis and Sorrell, 2015; Druckman et al., 2011; Freire-Gonzáles, 2011; Lenzen and Dey, 2002; Mizobuchi, 2008). This approach uses the IO models to estimate the energy use and emissions that are 'embodied' in different goods and services.

However, IO models rest upon a number of simplifying assumptions, including a fixed production structure, fixed market prices and fixed nominal wages. As a result, they are limited in their potential to capture the full macroeconomic impacts of improved energy efficiency. For example, reduced energy requirements will reduce the current cost of energy for consumers, who may seek a higher level of comfort by using a portion of the energy they originally saved. To assess these broader, economy-wide implications of improved energy efficiency, a Computable General Equilibrium (CGE) approach is preferred, since this relaxes some of assumptions that restrict other analytical methods. CGE models are based upon IO models, but (unlike the latter) are able to simulate adjustments to prices and other variables, together with substitution between different inputs. CGE models typically simulate a regional or national economy but can be extended to the multi-regional level.

CGE models are large-scale numerical economic models that capture the interaction among key economic actors within an economy, such as industries, final consumers, government, markets for factors of production and external transactors (imports/exports). The behaviour of an economic actor is described by mathematical functions based on rigorous economic theory. These models are parametrised on data from the real world and solved numerically with the help of computer software. The solution is found under the assumption that 
the represented markets within the economy are simultaneously in equilibrium. CGE models can simulate the impact of policies such as improvements in energy efficiency and capture, in principle, the impact and ramification of such policy in different components of the economy. Results from simulations may be sensitive to assumptions regarding the specification of the model and the availability of estimates for key exogenous parameters. Therefore, a sensitivity analysis of those assumptions is a key element of the majority of research works using CGE models.

A growing number of studies have used CGE models to identify the potential economy-wide impacts of energy efficiency improvements (see for example Allan et al., 2007; Anson and Turner, 2009; Broberg et al., 2015; Glomsrød and Taoyuan, 2005; Grepperud and Ramussen, 2004; Hanley et al., 2009; Koesler et al., 2016; Turner, 2009; Yu et al., 2015). The typical approach is to compare the economy-wide energy consumption in a baseline scenario to that in a scenario that includes an energy efficiency improvement in one or more sectors. A common characteristic of these studies is their primary focus on industrial energy efficiency improvements. Household energy efficiency has received much less attention, with only a handful of studies to date (Duarte et al., 2016; Dufournaud et al., 1994; Koesler, 2013; Lecca et al., 2014). This is one of the main drivers of our decision to focus on household energy efficiency.

\section{Household energy efficiency improvements in the UK - can public support be justified?}

In the first of two case studies presented in this chapter, we focus on the UK as a whole. We identify five household income groups based on their gross weekly equivalised income. ${ }^{5}$ In the case of UK households, the majority of the energy purchases are for residential use, i.e. lighting, cooking and heating. However, as the weekly income rises, so does the portion of energy spending for mobility purposes. Furthermore, the lowest-income households spend a larger portion of their disposable income on energy than the more affluent ones (energy spending 7 per cent of total consumption for the lowest-income households and 4 per cent for the highest-income ones).

We explore the impact of increasing the efficiency of household energy use in the UK so that they can run their homes (heat, cook, light etc. $)^{6}$ while using 10 per cent less physical energy. We examine two cases, one where all households receive the energy efficiency improvement (Scenario a) and a second where only the lowest-income group (20 per cent of UK households with the smallest weekly income) becomes more energy efficient (Scenario b). We initially study the impact of energy efficiency in isolation, by neglecting the capital and other costs associated with enabling energy efficiency (e.g. the installation of new boilers, or insulation). ${ }^{7}$ For the purpose of our work, the focus is solely on the energy use within the UK, not considering the energy embodied in imported goods.

Reducing the energy requirements of households frees up a portion of the disposable income of each household, which in turn can be spent elsewhere. 
Because of the higher purchasing power of the households, we observe an increase in the demand for UK and imported goods and services. ${ }^{8}$ This leads to a demand-driven expansion of the UK economy. As suggested by the IEA Multiple Benefits framework (IEA, 2014), an energy efficiency improvement in households delivers a multitude of macroeconomic benefits for the UK. Table 9.1 summarises the estimated changes in some key macroeconomic indicators due to the improvement in household energy efficiency. These are presented for two conceptual periods, the short run (SR) where industry capital stocks are fixed, and the long run (LR) where industry capital stocks are fully adjusted to the new macroeconomic equilibrium.

As can be seen in Table 9.1, at least in the LR when the economy has reached a new equilibrium, we observe a gross domestic product (GDP) expansion regardless of the target of the efficiency improvement. This implies increased employment and investment, as the sectors where the households spend their realised savings adapt to meet the increased demand. There is a

Table 9.1 Percentage change in key macroeconomic variables, relative to the baseline scenario, following a costless 10 per cent increase in household residential energy efficiency

\begin{tabular}{lrrrr}
\hline & \multicolumn{2}{c}{ Scenario $a$} & \multicolumn{2}{c}{ Scenario $b$} \\
\hline & SR & LR & SR & LR \\
\hline GDP & 0.03 & 0.16 & 0.00 & 0.02 \\
Consumer Price Index (CPI) & 0.32 & 0.21 & 0.03 & 0.01 \\
Investment & 1.14 & 0.79 & 0.15 & 0.11 \\
Unemployment rate & -0.82 & -2.08 & 0.04 & -0.13 \\
Employment & 0.05 & 0.13 & 0.00 & 0.01 \\
Nominal wages & 0.42 & 0.45 & 0.02 & 0.03 \\
Imports & 0.70 & 0.58 & 0.07 & 0.05 \\
Exports & -0.49 & -0.37 & -0.04 & -0.02 \\
Total energy use & -0.67 & -0.89 & -0.09 & -0.11 \\
Disposable income (excluding savings) & 0.52 & 0.58 & 0.06 & 0.07 \\
Household total energy consumption & -1.66 & -1.87 & -0.22 & -0.24 \\
Residential energy consumption & -2.35 & -2.62 & -0.30 & -0.33 \\
Household rebound in residential energy & 76.53 & 73.82 & 79.03 & 76.71 \\
Household rebound in total energy $^{\text {Economy wide rebound }}{ }^{1}$ & 78.89 & 76.33 & 80.65 & 78.50 \\
& 69.86 & 59.68 & 71.94 & 63.91 \\
\hline
\end{tabular}

Source: the authors.

Note

1 Rebound occurs when the potential energy savings from an increase in energy efficiency are bigger than the actual energy savings. In this study we calculate the rebound effect as $\left(1-\frac{A E S}{P E S}\right) \times 100$, where AES are actual energy savings and PES are potential energy savings.

Depending on what is included in actual energy savings, it is possible to obtain different definitions of rebound. For instance, the rebound in residential energy use only considers savings in the residential sector, while the economy wide rebound considers energy savings in the whole economy. See Figus et al. (2017b) Appendix D for details. 
significant difference in the level of expansion when only the lowest-income households are targeted (Scenario b) compared to the case where all the households receive the efficiency improvement (Scenario a). The explanation for this difference is that low-income households only account for a rather small portion of UK household consumption. In addition, the lowest-income households benefit less from the increases in wages and capital income as they rely more on transfers from the government, which are fixed in real terms. However, increased energy efficiency in the lowest-income households and the subsequent increase in demand has some impact on the income of other household groups, and this gives some additional momentum to the economic stimulus.

However, improving energy efficiency does not imply that there are only positive outcomes. Examining the Consumer Price Index (CPI), it is clear that increased demand for goods and services leads to an increase of output prices. This reduces the competitiveness of UK production sectors and consequently the level of exports. Moreover, it can be seen that even though physical energy requirements have been reduced by 10 per cent, the actual reduction of residential energy used is much smaller (around 2.62 per cent in the case where all households are targeted). This implies a significant rebound ( $>70$ per cent) that is driven by the fact that the price of energy ${ }^{9}$ is relatively lower, thus creating an incentive to consume more energy which especially benefits those households that are under-heating their properties, or in general did not fully meet their energy needs. In addition, to produce the additional goods and services which households consume, additional energy use by industry is necessary. But while the energy used by non-energy firms increases, the energy used by energy industry itself falls. This is because the reduction in energy demand in the residential sector more than offsets the increase in demand in industries. The net result is a reduction in the total energy used by industry. For this reason, the economywide rebound is smaller than the household rebound.

Our findings clearly demonstrate that improving energy efficiency simultaneously delivers energy savings, albeit less than what was technically feasible, together with wider macroeconomic benefits. It is important to point out that the economic expansion depicted in Table 9.1 does not imply that all sectors are experiencing increased activity. The difference between the household rebound and the economy-wide rebound demonstrates that overall industrial energy demand falls as a result of the increased energy efficiency in the residential sector.

So far, we have analysed the impact of improved household energy efficiency in isolation, without accounting for the cost of implementation. Since the role of energy efficiency is gaining increasing policy attention (see for example the Energy Efficient Scotland programme ${ }^{10}$ ), it is likely that those implementation costs will be funded by the public budget. Especially for low-income households that are interested in adopting efficiency improvements but who lack the funds to invest in improving their energy efficiency, the intervention of public spending is necessary. Assuming that the government would be reluctant to increase its deficit, we explore two main funding options: reallocation of existing government spending and increased income tax. 
In the case of reallocation of existing spending, the government funds the energy efficiency improvements by spending less on other goods and services. This reallocation is only temporary, five years, assuming that by the sixth year the efficiency improvement programme has been completed and paid for. The temporary reduction in government spending leads to a SR contraction in GDP. However, we assume that UK producers have perfect foresight. ${ }^{11}$ As a result, they anticipate that the reduction in government spending is temporary and adjust their investment strategy accordingly. This leads to a GDP contraction shorter than the five-year period. Once the full cost of the energy efficiency improvements has been covered, i.e. after the five-year period, the LR results are identical to the ones presented in the costless case. Thus, it is evident that a temporary disturbance in government spending, and therefore the economy as a whole, to fund energy efficiency improvements, ultimately leads to permanent positive outcomes across the economy.

The other funding option we explore is a temporary increase in income tax. This allows the government to continue spending at the same level as before, while generating additional revenue to fund energy efficiency improvements. Additionally, since households benefit from the energy efficiency improvement of their dwellings, an increased income tax is an indirect way to make households pay for those improvements. It is important to note that increased income tax has distributional effects as higher-income households pay more tax. Furthermore, in the case where only the lowest-income households receive the efficiency improvement, the implication is that all the other households are paying for actions that they receive no, or at least limited benefits from. Under this funding option, our findings indicate an initial contraction of economic activity. This is due to the fact that increased income tax reduces the take-home wage of workers who in turn demand higher wages, thereby raising the production costs of industrial sectors. When all households benefit from energy efficiency improvements, the LR results are close to those observed in the costless case. However, when only lowest-income households receive the energy efficiency improvements, the associated demand boost is insufficient to compensate for the increased income tax, with the result that LR GDP is marginally $(-0.005$ per cent) below the original level. One of the drivers of this observation is made clear when examining the changes in the disposable income of the different household groups. The poorest 20 per cent of households experience a SR increase in disposable income of 0.58 per cent. On the other hand, all the other household groups experience reductions in their disposable income, which persist even after the income tax is reverted to the original level.

\section{Household energy efficiency improvements in Scotland - a regional economic policy tool?}

Our second case study focuses on Scotland as a devolved nation within the UK. We use a CGE model ${ }^{12}$ that simulates the structure of the Scottish economy to investigate the impacts across that economy of energy efficiency improvements 
in Scottish households. Since the movement of workers between Scotland and the rest of the UK regions is relatively free of frictions, we assume that workers can freely migrate in and out Scotland from/to the rest of the UK. We model the net interregional migration of workers in response to the difference between the national and the regional unemployment rate and real wage. We assume that workers will migrate to the region that has the lowest unemployment rate and the highest real wage. A second important difference is that instead of disaggregating households into income groups, we identify a single representative Scottish household category. We assume that a costless energy efficiency improvement takes place that allows these households to achieve the same level of comfort and/or services while using 5 per cent less physical energy. ${ }^{13}$

In the base case scenario, we assume that the Scottish government spending is fixed. Changes to tax revenues are transferred to the central government in Westminster. Essentially, this reflects the fiscal arrangement between Scotland and the UK before April 2016. We call this FIXGOV.

Simulation results are reported in the second and third column of Table 9.2. Simulation results show SR results that are qualitatively similar to the UK case above (Scenario a). The 5 per cent energy efficiency improvement leads to a small expansion of the Scottish GDP (0.04 per cent), driven by an increase of household consumption by 0.3 per cent. This drives a net increase in investment

Table 9.2 Percentage change in key macroeconomic variables following a 5 per cent increase in Scottish household energy efficiency under alternative fiscal regimes

\begin{tabular}{|c|c|c|c|c|c|c|}
\hline \multirow[t]{2}{*}{ Time period } & \multicolumn{2}{|c|}{ FIXGOV } & \multicolumn{2}{|c|}{ FIXBAL } & \multicolumn{2}{|c|}{ TAX } \\
\hline & SR & $L R$ & $S R$ & $L R$ & SR & $L R$ \\
\hline GDP & 0.04 & 0.17 & 0.05 & 0.26 & 0.05 & 0.39 \\
\hline Consumer Price Index (CPI) & 0.08 & 0.00 & 0.10 & 0.00 & 0.11 & -0.08 \\
\hline Unemployment rate & -0.24 & 0.00 & -0.31 & 0.00 & -0.34 & 0.00 \\
\hline Total employment & 0.06 & 0.18 & 0.08 & 0.27 & 0.09 & 0.39 \\
\hline Nominal gross wage & 0.11 & 0.00 & 0.14 & 0.00 & 0.12 & -0.19 \\
\hline Real gross wage & 0.03 & 0.00 & 0.04 & 0.00 & 0.04 & 0.00 \\
\hline Household consumption & 0.30 & 0.42 & 0.35 & 0.48 & 0.40 & 0.66 \\
\hline Investment & 0.12 & 0.17 & 0.17 & 0.23 & 0.22 & 0.38 \\
\hline Exports & -0.12 & 0.00 & -0.14 & 0.00 & -0.15 & 0.14 \\
\hline Non-energy industries output & 0.07 & 0.19 & 0.09 & 0.27 & 0.09 & 0.39 \\
\hline Energy industries output & -0.41 & -0.41 & -0.41 & -0.37 & -0.40 & -0.22 \\
\hline Energy use & -0.89 & -0.57 & -0.87 & -0.51 & -0.85 & -0.36 \\
\hline Energy demand by producers & -0.22 & -0.24 & -0.22 & -0.19 & -0.21 & -0.03 \\
\hline Energy demand by households & -2.70 & -1.47 & -2.65 & -1.41 & -2.60 & -1.26 \\
\hline Government expenditure & - & - & 0.06 & 0.24 & - & - \\
\hline Government budget & 53.70 & 165.50 & - & - & - & - \\
\hline Income tax & - & - & - & - & -0.10 & -0.45 \\
\hline Household rebound & 46.03 & 70.53 & 46.94 & 71.82 & 47.97 & 74.82 \\
\hline Economy-wide rebound & 27.65 & 53.62 & 29.01 & 58.14 & 30.69 & 70.61 \\
\hline
\end{tabular}

Source: the authors. 
( 0.12 per cent), total employment $(0.06$ per cent) and nominal wages $(0.11$ per cent). Like in the UK case, the increase in wages puts upward pressure on output prices, so that Scottish sectors lose in terms of international competitiveness.

However, the initial increase in the real wage $(0.03$ per cent) together with the fall in the unemployment rate $(-0.24$ per cent $)$ triggers net in-migration. As workers migrate to Scotland, the real wage falls and the unemployment ${ }^{14}$ rate increases until in the LR they are back to their baseline values. The latter is a key finding as the decrease of output prices (driven by movement of labour) means that over time the competitiveness of Scottish industries is gradually restored and any negative impact on export activity is eliminated by the time the Scottish economy reaches a new equilibrium. However, restoration of export competitiveness implies additional demand from abroad for the outputs of Scottish sectors, which in turn requires the use of additional energy compared to the SR. Therefore, the initial energy savings are gradually eroded as the Scottish sectors increase their production to meet the export demand.

Up until this point, we have assumed that any budget savings ${ }^{15}$ realised by the Scottish government will be transferred to the central UK government. However, since April 2016 the devolved Scottish government has acquired the power to determine income taxes and use the revenue obtained. To explore what the potential impact of new fiscal powers could be in the case of increased household energy efficiency, we examine two ways in which the government could use the budget savings: they could be returned to the economy via increased government purchases (FIXBAL case) or via reductions in income taxes (TAX case). Table 9.2 summarises the key macroeconomic effects of these two uses of the budget savings, along with the standard case where savings are accumulated and returned to UK government (FIXGOV).

The results in Table 9.2 show that if the budget savings driven by the 5 per cent household energy efficiency improvement are returned to the economy via government purchases, this leads to increased government consumption of 0.06 per cent in the SR and 0.24 per cent in the LR. Essentially, the additional revenue obtained as a result of the energy efficiency-driven economic stimulus is recycled into the economy generating additional stimulus. As a result, we observe larger increases in GDP, employment, investment and household consumption compared to the case where the budget savings are accumulated. However, the additional economic stimulus also leads to further erosion of the economy-wide energy savings achieved via this energy efficiency improvement.

In the case where we assume that the budget savings are returned to the economy via income tax reductions, we find that these are sufficient for a 0.1 per cent tax cut in the SR and 0.45 per cent in the LR. However, as discussed in the UK case study, changes in the income tax have impacts on both the demand and the supply side of the economy. On the demand side, a lower income tax means increased household disposable income and therefore increased consumption ( 0.66 per cent in the LR). This is significantly larger than both the FIXGOV and the FIXBAL approaches. At the same time, the increased net-of-tax wage of households puts downward pressure on the demand for higher 
wages. This reduces the cost of labour and stimulating production and employment. Moreover, due to the competitiveness boost of reduced labour costs, the export activity of Scottish industries is also stimulated. Overall, a reduction in income tax delivers significantly greater economic stimulus than the other two cases, which in turn is associated with greater increases in employment, investment and other variables. However, the additional production also requires the use of additional resources including, but not limited to, energy.

In general, we find that greater fiscal autonomy allows for greater economic expansion from the efficiency improvements, when the government uses the additional revenue from taxes to increase current government spending or reduce the income tax rate. However, the extent to which those improvements reduce economy-wide energy consumption is inversely proportional to size of the economic expansion.

\section{A saving multiplier as an alternative to rebound indicator}

These case studies in the previous section demonstrate that the erosion of the energy savings achieved from improved energy efficiency largely depends on how the economy reacts to the increased disposable income of households, and/ or to the reduced energy costs for industries. It has been also indicated that a number of studies (see Madlener and Turner, 2016; Sorrell, 2007; Turner, 2013 for reviews) have sought to identify the indirect and wider economic rebound of increased efficiency in both consumptive and productive energy use. IO analytical techniques were often used to conduct such studies (e.g. Chitnis et al., 2013, 2014; Druckman et al., 2011; Freire-Gonzáles, 2011; Lecca et al., 2014; Lin and Du, 2015; Pfaff and Sartorius, 2015; Thomas and Azevedo, 2013a, 2013b), but all of them have used the rebound effect to estimate the effectiveness of energy efficiency and gauge the impact across the different supply chains.

The problem with rebound as an indicator is that it solely focuses on what we fail to achieve from efficiency improvements, rather than what we actually achieve. It is not surprising, therefore, that the concept has generated resistance from policymakers. Moreover, there is no standardised approach to estimate rebound effects. Most studies calculate rebound as the ratio of the 'actual energy savings' over the 'potential energy savings'. While actual energy savings can be accurately calculated in an energy-economic modelling framework, problems arise when 'potential energy savings' need to be determined. The main issue revolves around the energy used by energy producers to produce output. Following an energy efficiency improvement, the demand for the output of energy producers falls and as a result we observe quantity adjustments on the energy used by those industries. Guerra and Sancho (2010) argue that these quantity adjustments need to be included in the 'potential energy savings', whereas Turner (2013) argues that they should be reflected in the actual and not the 'potential energy savings'. Different studies adopt different approaches in specifying the 'potential energy savings' that in turn contribute to the divergence in rebound estimates. This leads to conflicting messages to policymakers. 
The aforementioned issues could be partly addressed by using a 'multiplier approach', especially in cases where IO is used as the methodological framework. Multiplier analysis is commonly used by policymakers in a range of areas, such as estimating how many jobs are created across the economy for a set number of jobs created in a specific sector. Multiplier analysis relies upon IO models and is therefore limited by the assumption that prices and wages remain constant. However, the policy community is familiar with this approach and it relies upon relatively straightforward calculations. These are desirable qualities when studying the impacts of improved energy efficiency, since inconsistencies in calculation methods contribute to the existing confusion. As an alternative then to rebound, we propose the use of a Carbon (Energy) Saving Multiplier (CSM).

In our work, CSM is calculated using an interregional IO table from the World Input Output Database project (Timmer et al., 2015). This version of the table we used for our work captures the economic interrelationships between 35 sectors in 41 countries and regions, together with the associated energy use and carbon emissions. We define as CSM the ratio of the direct and global supply chain carbon savings over the direct carbon savings. Direct are the carbon savings that occur at the point where the efficiency improvement takes place (e.g. Agriculture sector or households) and supply chain savings are the ones that occur in the domestic and international upstream supply chains, as a result of the reduction in energy demand. For household energy efficiency improvements, the CSM measures the domestic and international reduction in carbon emissions following a unit reduction in emissions at the household level.

To illustrate the use of the CSM, we use the example of a 10 per cent reduction in UK household demand for the outputs of the UK 'Electricity Gas and Water Supply' (EGWS) sector. This corresponds to $\$ 5,525.8$ million less spending on the sector (Table 9.3) and reduces household $\mathrm{CO}_{2}$ emissions by 6,172 kilotonnes (kt). Reduced demand for EGWS output means reduced EGWS production and therefore reduced demand from its upstream supply chain, both domestic and international. As a result, a total saving of $16,625 \mathrm{kt}$ of $\mathrm{CO}_{2}$ is achieved globally. This means that for each kt of $\mathrm{CO}_{2}$ saved by UK households, $2.69 \mathrm{kt}$ of $\mathrm{CO}_{2}$ are saved globally - which is the CSM.

As demonstrated by this example, the CSM is defined in such a way that clearly shows what needs to be included in the numerator and the denominator, helping to avoid inconsistencies in its calculation. Moreover, it focuses on savings achieved (in this case carbon) rather than savings missed. The CSM remains constant even if we assume that the households, or any targeted sector, opt to use a part of the initially realised monetary savings for more heating, lighting, cooking or water (i.e. a direct rebound). As seen in Table 9.3, even if we assume a 10 per cent or a 50 per cent rebound (take back of original demand reduction) the direct and supply chain savings are eroded but the CSM remains the same. ${ }^{16}$

What actually changed the CSM are the re-spending decisions of households. To illustrate, we explored an alternative scenario where households spend all of the cost savings from the efficiency improvements on hotels and restaurants. 


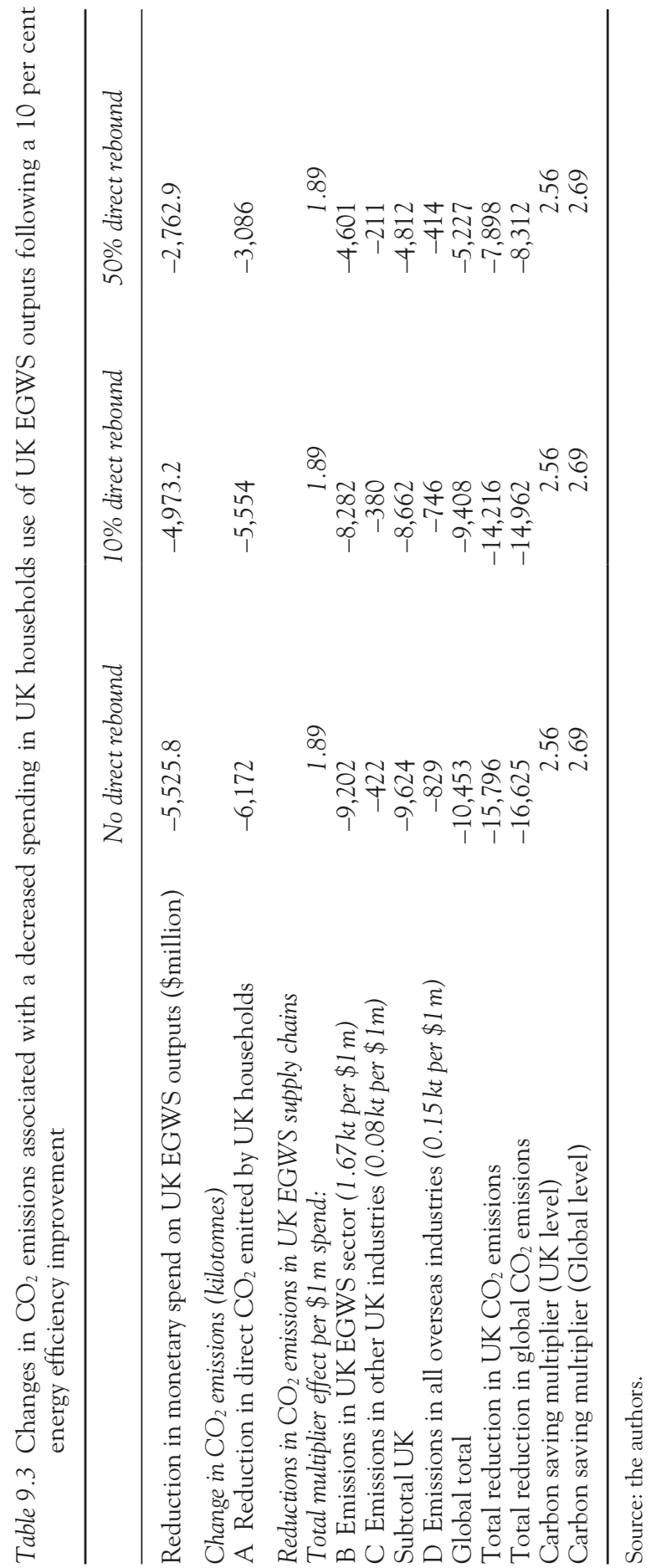


This leads to an increase of $514 \mathrm{kt}$ in $\mathrm{UK} \mathrm{CO}_{2}$ emissions and $794 \mathrm{kt}$ globally. These findings indicate a more significant impact in the domestic supply chains than the international ones, signalling that the hotel and restaurant sector relies more on domestic suppliers than overseas. This finding is also reflected in the erosion of the CSM. The domestic CSM is eroded by 4 per cent (from 2.56 to 2.48) while the global one is eroded by 3 per cent (from 2.69 to 2.57), demonstrating a larger impact within the UK compared to abroad.

In general, the methodological procedure used to calculate the $\mathrm{CSM}^{17}$ not only allows us to estimate the effectiveness of energy efficiency improvements, but also enables the disaggregation of the impacts along different supply chains. This way we can gain a better understanding on which sectors and in which nations are more likely to be impacted by an efficiency improvement and any subsequent re-spending decisions.

\section{Conclusions and policy recommendations}

In this chapter, we have discussed how rebound as a standalone indicator of the effectiveness of energy efficiency policies can be misleading and ultimately discouraging for policymakers. A focus on rebounds highlights the failure to achieve the technologically feasible energy use reductions but neglects the wider range of economic and social benefits that energy efficiency improvements can deliver. As our work has shown, energy efficiency improvements can contribute to a range of policy objectives, beyond climate change alone.

As shown in our UK case study, household energy efficiency improvements can provide a stimulus to a country's economy, as IEA (2014) suggests is possible, leading to increases in employment, investment and wages, while achieving a substantial, yet smaller than anticipated, reduction in energy use. This observed rebound effect is not indicative of the failure of energy efficiency policy, rather it is a necessary companion to the broader improvements in social welfare that the efficiency improvements provide.

Through this work, we have also highlighted that the magnitude of the benefits largely depends on the number and the purchasing power of the beneficiaries of energy efficiency. When the policy targets all households in an economy we achieve the maximum socio-economic benefits - which are likely to be substantial enough to cover the public funds required to support the efficiency improvement. However, policy often targets less privileged households that are less likely to be able to afford the efficiency improvement. In this case, our findings indicate that the energy efficiency improvement provides a smaller stimulus to the economy, while improving the welfare of low-income households through, for example, warmer homes. In the case where only the lowest-income households benefit from the improvement, it is of paramount importance to carefully design the policy and how it will be funded. Our research has shown that funding via increased taxation can be disruptive for the economy, leading to a slight reduction in economic activity, despite the realised benefits for low-income households. On the other hand, a reallocation of existing funds ultimately leads to an economic stimulus. 
At the regional level, energy efficiency can also have expansionary impact to the economy. However, the greater openness in the goods and labour markets leads to differences in some of the indicators. Most notably, at the national level we observed a LR reduction in export activity due to a rise in prices, which is not observed when studying a region. The in-flow of labour puts downward pressure on wages and therefore prices leading to LR export levels that are on par to the pre-efficiency ones. Apart from that, even at the regional level, energy efficiency improvements deliver benefits in terms of GDP, employment, investment and household consumption increases, while also fulfilling the climate change policy role by driving reductions in economywide energy use. It can be seen then that energy efficiency can be used as an instrument for regional development.

Part of the regional, and national, benefits gained by energy efficiency improvements are the increased revenue from taxes due to increased production. This additional fiscal space could prove to be a useful tool to achieve further economic stimulus for the regional economy, provided that the region has the authority to use the accumulated budget savings. As we saw by exploring two different options, recycling the realised budgets savings has the potential to provide not just a demand-driven stimulus to the economy, if the savings are returned as increased government purchases, but also a permanent boost to competitiveness if the savings lead to a reduction of income tax rates. In any case, the combination of energy efficiency improvement and recycling of the accumulated budget savings from this improvement are useful policy tools in achieving macroeconomic targets for the regional economy.

Our findings are in agreement with the IEA claims that energy efficiency can deliver, among other things, macroeconomic benefits for the wider economy. We have found this to be the case both for regional and national economies. It is important to keep in mind that this by no means implies that the entirety of the economy will be better off following an energy efficiency improvement. Instead, there will be winners and losers, with the energy sectors facing a drop in activity and, in some cases, particular household groups. Overall, energy efficiency improvement is beneficial for both the economy and the environment, and this should be a strong incentive for policymakers to support such policies, always following careful consideration of the funding and what its impact might be.

However, even though research such as ours demonstrates the macroeconomic benefits of energy efficiency, the use of rebound as an indicator of its effectiveness could still create barriers to the support of such policies. In an attempt to resolve this issue, we proposed and demonstrated the use of an alternative metric, the CSM. CSM makes use of multiplier analysis, a familiar analytical tool for policymakers, to focus attention on the carbon or energy savings achieved, rather than failed to be achieved, while providing a fuller set of information to policymakers. This includes the spatial breakdown of the savings and/or any impacts from re-spending, along with the full set of information provided by the rebound indicator. Of course, there are limitations on the way in 
which the CSM is calculated and used, but the combination, in future research projects, of CSM with the CGE models used for our two case studies, could resolve the existing issues.

In summary, our project leads us to four main conclusions.

1 The rebound effect could be a misleading indicator in that it only accounts for the 'negative' portion of the outcome of an efficiency improvement in energy use. Evaluations of energy efficiency programmes should adopt a holistic approach and carefully assess the full range of benefits and costs of such programmes without focusing solely on a single indicator.

2 Improving household energy efficiency delivers both reduced energy use and increased economic activity. However, there is typically an inverse relation between the energy savings achieved and the size of the economic expansion. A bigger economy requires more inputs such labour and capital but also energy and other intermediate inputs.

3 Government-funded energy efficiency programmes can help low-income households who are not able to heat their homes properly. In addition, they can be used as a means of economic stimulus. However, the way in which the necessary funds are raised must be weighed carefully against the benefit of a more efficient use of energy.

4 Alternative measures such as the CSM can highlight the positive impact of energy efficiency improvements by focusing on the achieved savings in energy use and carbon emissions. This can be used as alternative to the rebound indicator and, in conjunction with other macroeconomic indicators, provide policymakers with a more comprehensive picture of the likely impact of energy efficiency measures.

\section{Acknowledgements}

The authors acknowledge support from the UK Engineering and Physical Sciences Research Council (EPSRC grant ref. EP/M00760X/1), Economic and Social Research Council (ESRC PhD Studentship ref. 1562665) and Natural Environment Research Council (ESRC-NERC PhD Studentship, ref. [ESRC] 1207166). We also acknowledge the support of ClimateXChange, the Scottish Government-funded Centre for Expertise in Climate Change. Please note that the opinions in this chapter are the sole responsibility of the authors, and not necessarily those of the ClimateXChange or the Scottish government.

\section{Notes}

1 Reducing the need for energy would reduce the emissions associated with the generation and use of this energy.

2 While this specific terminology originates with the IEA (2014), arguments and evidence that energy efficiency will enhance economic welfare in a range of ways, including as a result of macroeconomic expansion, have been considered in other studies, notably (in terms of reflecting on the recent dominant focus on rebound effects) in the recent contribution by Gillingham et al. (2016). 
3 Consumer surplus is the difference between what people are willing to pay for a good and what they actually pay.

4 As will be discussed in the relevant section, it is possible to spatially disaggregate the total carbon or energy savings, so that we observe the impact in a national or international level.

5 To disaggregate the households in the CGE model, data from the Office for National Statistics (ONS) Living Costs and Food Survey have been used. The methodology used by ONS is described in the technical reports that can be found here: www.ons.gov.uk/ peoplepopulationandcommunity/personalandhouseholdfinances/incomeandwealth/ methodologies/livingcostsandfoodsurvey\#technical-report. Detailed information on the CGE model used for this case study can be found at Figus et al. (2017).

6 The energy required to run a house constitutes what we refer to as residential energy. The key difference between a household's residential energy use and total energy use is that in total energy use we include the energy required for private transportation purposes.

7 Note that, while the enabling phase constitutes a temporary cost, the achieved efficiency can be considered as permanent, at least throughout the lifetime of the accommodation.

8 We assume that UK and imported goods and services are imperfect substitutes. As a result, UK consumers are more likely to turn to UK outputs rather than imported ones to spend their energy savings.

9 Note that here we refer to both the reduction in the effective price of residential energy services driven by the increase in energy efficiency, and the reduction in the market price driven by the fall in demand for energy.

10 Details on the programme and its route map are available online at: www.gov.scot/ Resource/0053/00534980.pdf.

11 This reflects a situation where the government announces in advance its intention to divert some of the current spending to fund energy efficiency improvements for only 5 years. This allows firms to have a clear vision of how future government spending are going to be allocated and to plan investment accordingly.

12 For a detailed exposition of the CGE model used please refer to Figus et al. (2018).

13 Differently from the UK case above, here we consider household energy efficiency improvements in all household energy use, including private transport. Hence, we call this household energy efficiency rather than residential.

$14 \mathrm{We}$ assume that wages respond immediately to changes in the economy. On the other hand, we assume that there is a single modelling period (year) lag in the migration response as workers observe the economic circumstances in the previous period and decide on whether to move or not in the current one. Essentially, migration occurs from year two onwards, until the labour market returns to equilibrium.

15 In our central scenario (FIXGOV) we assume fixed government spending, as also seen in Table 9.2. Therefore, any budget savings come from additional revenue from income taxes, indirect taxes on consumption goods etc.

16 This finding is accurate in an IO framework where we assume no changes in prices and wages. In a more sophisticated modelling approach such as CGE, which considers a wider set of changes within the economy, this finding might not be the same.

17 For a detailed discussion of the methodology used please see Turner and Katris (2017).

\section{References}

Allan, G., Hanley, N., McGregor, P., Swales, K. and Turner, K. (2007) The impact of increased efficiency in the industrial use of energy: A computable general equilibrium analysis for the United Kingdom. Energy Economics 29(4): 779-798. 


\section{Gioele Figus et al.}

Anson, S. and Turner, K. (2009) Rebound and disinvestment effects in refined oil consumption and supply resulting from an increase in energy efficiency in the Scottish commercial transport sector. Energy Policy 37(9): 3608-3620.

Brännlund, R., Ghalwash, T. and Nordström, J. (2007) Increased energy efficiency and the rebound effect: Effects on consumption and emissions. Energy Economics 29(1): 1-17.

Broberg, T., Berg, C. and Samakovlis, E. (2015) The economy-wide rebound effect from improved energy efficiency in Swedish industries: A general equilibrium analysis. Energy Policy 83: 26-37.

Chitnis, M. and Sorrell, S. (2015) Living up to expectations: Estimating direct and indirect rebound effects for UK households. Energy Economics 52(S1): 100-S116.

Chitnis, M., Sorrell, S., Druckman, A., Firth, S.K. and Jackson, T. (2013) Turning lights into flights: Estimating direct and indirect rebound effects for UK households. Energy Policy 55: 234-250.

Chitnis, M., Sorrell, S., Druckman, A., Firth, S.K. and Jackson, T. (2014) Who rebounds most? Estimating direct and indirect rebound effects for different UK socioeconomic groups. Ecological Economics 106: 12-32.

Druckman, A., Chitnis, M., Sorrell, S. and Jackson, T. (2011) Missing carbon reductions? Exploring rebound and backfire effects in UK households. Energy Policy 39(6): 3572-3581.

Duarte, R., Feng, K., Sanchez-Choliz, J., Sarasa, C. and Sun, L. (2016) Modelling the carbon consequences of pro-environmental consumer behaviour. Applied Energy 184: 1207-1216.

Dufournaud, C.M., Quinn, J.T. and Harrington, J.J. (1994) An Applied General Equilibrium (AGE) analysis of a policy designed to reduce the household consumption of wood in the Sudan. Resource and Energy Economics 16(1): 67-90.

Figus, G., Lecca, P., Turner, K. and McGregor, P.G. (2017a) Energy Efficiency as an Instrument of Regional Development Policy: Trading off the Benefits of an Economic Stimulus and Energy Rebound Effects. Discussion Paper 17.02, Department of Economics, University of Strathclyde, Scotland. Available at: www.strath.ac.uk/media/1newwebsite/ departmentsubject/economics/research/researchdiscussionpapers/17.02.pdf.

Figus, G., Lecca, P., McGregor, P. and Turner, K. (2018) Energy efficiency as an instrument of regional development policy? The impact of regional fiscal autonomy. Regional Studies: 1-11. DOI: 10.1080/00343404.2018.1490012.

Figus, G., Turner, K., McGregor, P.G. and Katris, A. (2017b) Making the case for supporting broad energy efficiency programmes: Impacts on household incomes and other economic benefits. Energy Policy 111: 157-165.

Freire-González, J. (2011) Methods to empirically estimate direct and indirect rebound effect of energy-saving technological changes in households. Ecological Modelling 223(1): 32-40.

Gillingham, K., Rapson, D. and Wagner, G. (2016) The rebound effect and energy efficiency policy. Review of Environmental Economics and Policy 10(1): 68-88.

Glomsrød, S. and Taoyuan, W. (2005) Coal cleaning: A viable strategy for reduced carbon emissions and improved environment in China? Energy Policy 33(4): 525-542.

Grepperud, S. and Rasmussen, I. (2004) A general equilibrium assessment of rebound effects. Energy Economics 26(2): 261-282.

Guerra, A.I. and Sancho, F. (2010) Rethinking economy-wide rebound measures: An unbiased proposal. Energy Policy 38(11): 6684-6694.

Hanley, N., McGregor, P.G., Swales, J.K. and Turner, K. (2009) Do increases in energy efficiency improve environmental quality and sustainability? Ecological Economics 68(3): 692-709. 
IEA (2014) Capturing the Multiple Benefits of Energy Efficiency: A Guide to Quantifying the Value Added. IEA, Paris, France.

Jevons, W.S. (1865) The Coal Questions-Can Britain Survive? Macmillan and Co., London, UK.

Khazzoom, J. (1980) Economic implications of mandated efficiency in standards for household appliances. The Energy Journal 1(4): 21-40.

Koesler, S. (2013) Catching the Rebound: Economy-wide Implications of an Efficiency Shock in the Provision of Transport Services by Households. Centre for European Economic Research. Discussion Paper No. 13-082.

Koesler, S., Swales, K. and Turner, K. (2016) International spillover and rebound effects from increased energy efficiency in Germany. Energy Economics 54: 444-453.

Lecca, P., McGregor, P.G., Swales, J.K. and Turner, K. (2014) The added value of a general equilibrium analysis of increased efficiency in household energy use. Ecological Economics 100: 51-62.

Lenzen, M. and Dey, C.J. (2002) Economic, energy and greenhouse emissions impacts of some consumer choice, technology and government outlay options. Energy Economics 24(4): 377-403.

Lin, B. and Du, K. (2015) Measuring energy rebound effect in the Chinese economy: An economic accounting approach. Energy Economics 50: 96-104.

Madlener, R. and Turner, K. (2016) After 35 Years of Economic Energy Rebound Research: Where Do We Stand? In: Santarius, T., Walnum, H.J. and Aall, C. (Eds) Rethinking Climate and Energy Policies. Springer International Publishing, Cham, Switzerland.

Mizobuchi, K. (2008) An empirical study on the rebound effect considering capital costs. Energy Economics 30(5): 2486-2516.

Pfaff, M. and Sartorius, C. (2015) Economy-wide rebound effects for non-energetic raw materials. Ecological Economics 118: 132-139.

Sorrell, S. (2007) The Rebound Effect: An Assessment of the Evidence for Economywide Energy Savings from Improved Energy Efficiency. Technical Report 4, UK Energy Research Centre, London, UK.

Thomas, B.A. and Azevedo, I.L. (2013a) Estimating direct and indirect rebound effects for U.S. households with input-output analysis part 1: Theoretical framework. Ecological Economics 86: 199-210.

Thomas, B.A. and Azevedo, I.L. (2013b) Estimating direct and indirect rebound effects for U.S. households with input-output analysis part 2: Simulation. Ecological Economics 86: 188-198.

Timmer, M.P., Dietzenbacher, E., Los, B., Stehrer, R. and de Vries, G.J. (2015) An illustrated user guide to the world input-output database: The case of global automotive production. Review of International Economics 23(3): 575-605.

Turner, K. (2009) Negative rebound and disinvestment effects in response to an improvement in energy efficiency in the UK economy. Energy Economics 31(5): 648-666.

Turner, K. (2013) 'Rebound' effects from increased energy efficiency: A time to pause and reflect. The Energy Journal 34(4): 25-42.

Turner, K. and Katris, A. (2017) A 'Carbon Saving Multiplier' as an alternative to rebound in considering reduced energy supply chain requirements from energy efficiency? Energy Policy 103: 249-257.

Yu, X., Moreno-Cruz, J. and Crittenden, J. C (2015) Regional energy rebound effect: The impact of economy-wide and sector level energy efficiency improvement in Georgia, USA. Energy Policy 87: 250-259. 


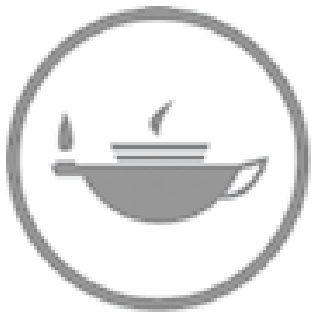

Taylor \& Francis Taylor \& Francis Group

http://taylorandfrancis.com 